\title{
Complementary feeding patterns in a developing country: a cross-sectional study across Lebanon
}

\author{
M. Batal, ${ }^{1}$ C. Boulghourjian ${ }^{2}$ and C. Akik ${ }^{2}$
}

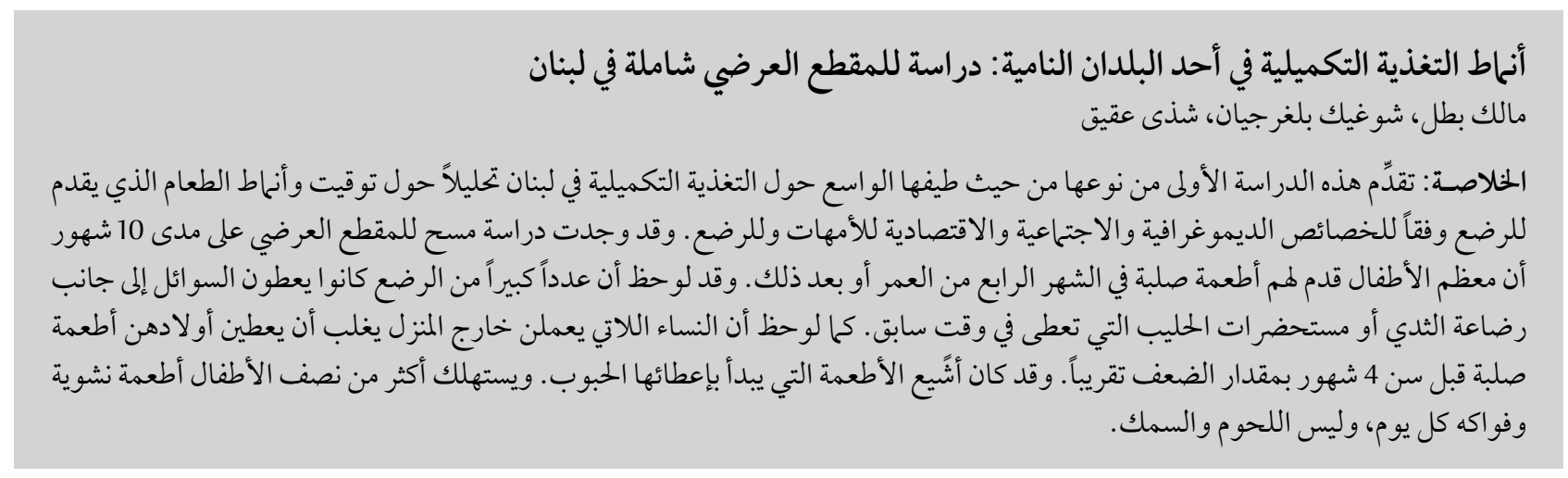

ABSTRACT This first, large-scale study on complementary feeding in Lebanon analysed the timing and types of food introduced to infants according to mothers' demographic and socioeconomic and infants' characteristics. A cross-sectional survey over 10 months found that the majority of infants were introduced to solid foods at or after 4 months of age. A large number of infants were given liquids other than breast or formula milk earlier. Women in employment outside the home were almost twice as likely to introduce solid foods before age 4 months. The most common starting food was cereals. More than half the children consumed starchy foods and fruits every day, but not meats and fish.

\section{Alimentation de complément dans un pays en voie de développement : une étude transversale au Liban}

RÉSUMÉ Cette première étude à grande échelle sur l'alimentation de complément, menée au Liban, analysait le moment d'introduction et le type de nourriture proposé aux nourrissons en fonction des caractéristiques démographiques et socio-économiques de la mère et des spécificités du nourrisson. Une étude transversale menée sur 10 mois a montré que chez la majorité des nourrissons, les aliments solides étaient introduits à partir de l'âge de quatre mois ou au-delà. Un grand nombre de nourrissons était alimenté avant quatre mois avec des liquides autres que du lait maternel ou du lait pour nourrissons. La probabilité que les femmes ayant un emploi en dehors de la maison introduisent des aliments solides avant l'âge de quatre mois était près de deux fois supérieure. Le plus souvent, les premiers aliments introduits étaient les céréales. Plus de la moitié des enfants consommait des féculents et des fruits chaque jour ; par contre, ils ne mangeaient ni viande, ni poisson. 


\section{Introduction}

Debate about the optimal duration of exclusive breastfeeding led the World Health Organization to carry out a systematic review in 2002 in which the authors concluded that 6 months is the ideal period [1]. Furthermore, there is consensus on the types of foods recommended for the transition from breast milk/formula to solid foods, with the majority of studies concurring that young children require foods that are energy- and nutrient-dense as opposed to thin gruels that can hinder the absorption of certain micronutrients [2].

Mothers in the developing world, however, are at risk of following inaccurate guidelines and misinformation. High rates of morbidity and poor growth and stunting more often than not have been attributed to poor weaning practices [3-5]. Although these morbidities have been reported for Lebanon as well [6], and some reports on feeding-related ailments have been published, such as the prevalence of diarrhoea and gastro-oesophageal reflux, no studies have examined their causes in relation to the types and quantities of foods provided to the very young child. Despite the high infant and under-5 morbidity rates due to feeding problems in Lebanon-58.0\% infant morbidity in the greater Beirut area [7] — complementary foods and feeding practices have not been given sufficient systematic consideration and there is very little documented information on these issues.

Lebanon has a total estimated population of 3677778 within an area of $10452 \mathrm{~km}^{2}$. The infant mortality rate is 27.4 per 1000 live births and life expectancy is 71.8 years. The economy of Lebanon is recuperating from 15 years of civil war, which has led to a reduced per capita income [8].

This is the first, large-scale and extensive report on complementary feeding practices in Lebanon to identify the patterns of introduction of solid foods, the demographic, socioeconomic and infant characteristics influencing these practices, and the types of complementary foods provided to infants and young children in Lebanon.

\section{Methods}

\section{Study sample}

Two-stage sampling was conducted to select participants. Out of the 80 health centres operated by the Ministry of Social Affairs receiving patients of low to middle socioeconomic status, a random sample of 20 health centres was selected. Mothers who visited the health centres on the day the research team was there and who met the criteria for inclusion were randomly recruited to participate in the research. Inclusion criteria were: having a last child between 1 and 5 years of age (index child) and gestational age at birth $\geq 37$ weeks.

A total of 1000 participants were randomly selected; $17 \%$ were excluded due to incomplete questionnaires and refusal to participate. Chi-squared tests were performed and no significant differences were found between these women and the participants.

\section{Data collection}

The survey was administered over 10 months in 2003-04. All interviews were conducted by dieticians trained in standard data collection techniques and ensured that all sociodemographic questionnaires were completely filled in. The aim of the study was explained and consent was requested from all mothers before interview. Information on all variables was collected at the health centres.

\section{Questionnaire design}

The questionnaire included 9 sections: (i) information about all children in the family: number, sex and how many were breastfed; (ii) information about the index child (born 1-5 years ago): age, sex, place of birth, who attended the birth, type of delivery, use of analgesics, height and weight of child at birth; (iii) information about breastfeeding patterns for the index child: timing of first breastfeeding, period of exclusive breastfeeding, other liquids given to the infant, timing of introduction of solid foods, source of advice for introduction of solid foods, duration of breastfeeding, reason for termination of breastfeeding; (iv) hospital delivery practices related to breastfeeding: liquid first given to infant postdelivery, hospital influence on this choice, provision of formula milk in the hospital, provision of information while in the hospital about benefits of breastfeeding and methodology, encouragement by hospital staff to breastfeed within the first half hour post-delivery, rooming in, number of visits per day of infant to mother (in case of no rooming in); (v) the perceived benefits of and barriers to breastfeeding; (vi) the social encouragement to breastfeed from spouse, mother, mother-in-law, obstetrician/gynaecologist and paediatrician; (vii) patterns of introduction of solid food, including age and food frequency questionnaire; (viii) general information about the mother such as age, height, weight, nationality, religion, place of birth, place of residence, marital status, educational level, occupational status and whether the mother herself was breastfed; (ix) other demographic information such as education level and occupation of the father. Information from sections (i)-(iii) and (vii)-(ix) were used in this analysis.

The food frequency questionnaire recorded mother's recall of the frequencies of certain categories of food consumed by infants (cereals, fruits, dessert, dairy, vegetables, eggs, meat, legumes): every day; 4-6 times per week; 2-3 times per week; 1 time per week; seldom; never.

The questionnaire was pilot tested prior to the initiation of interviews, and changes were made accordingly. The validity and reliability of the questionnaire 
was examined with test-retest (Cronbach $\alpha=0.78)$, inter- $(\kappa=0.83)$ and intra-rater $(\kappa=0.82)$ reliabilities.

\section{Statistical analysis}

For statistical analysis SPSS, version 12.0 was used and all analyses were performed and reported by 1 person who had not been involved in data collection. The chi-squared statistic was used for testing the significance of cross-tabulations. Student $t$-tests were conducted for calculating mean differences. Nonparametric 1-way analysis of variance was performed to rank scores of the food frequency questionnaire with selected variables, and the Kruskal-Wallis test of chi-squared approximation was used to explain significant differences in the analysis. Multivariate logistic regression analysis was done to evaluate the associations between the infant's age at initiation of complementary feeding and maternal, childbirth and infant data. A dichotomous dependent variable was used by categorizing the infant's age at initiation of complementary feeding as $<4$ months of age and $\geq 4$ months of age, because at the time the study was carried out, the recommendations for introduction of solid foods were between 4 and 6 months [1]. The odds ratio (OR) and the $95 \%$ confidence interval (CI) for each independent variable were derived through regression analysis. An OR was considered significant if the $95 \% \mathrm{CI}$ did not include 1.

\section{Results}

\section{Maternal and child characteristics}

The characteristics of the study group are given in Table 1. The mean age of mothers was 30.8 years and their mean number of children was almost 5 . Almost all mothers were of Lebanese nationality and married. Many had less than high school education (53.6\%) and the great majority were homemakers.

\begin{tabular}{|c|c|c|}
\hline Characteristic & No. of responses & Value \\
\hline \multicolumn{3}{|l|}{ Infants } \\
\hline $\operatorname{Sex}(\%)$ & 825 & \\
\hline Boys & & 52.4 \\
\hline Girls & & 47.6 \\
\hline Mean (SD) birth weight (g) & 803 & $3314(588)$ \\
\hline Mean (SD) birth height $(\mathrm{cm})$ & 526 & $50.7(2.9)$ \\
\hline \multicolumn{3}{|l|}{ Mothers } \\
\hline Mean (SD) age (years) & 829 & $30.8(5.9)$ \\
\hline Mean (SD) nonpregnancy weight $(\mathrm{kg})$ & 781 & $64.0(11.7)$ \\
\hline Mean (SD height $(\mathrm{m})$ & 595 & $1.6(0.1)$ \\
\hline Mean (SD) no. of children & 830 & $4.9(1.6)$ \\
\hline Nationality (\%) & 830 & \\
\hline Lebanese & & 99.2 \\
\hline Marital status (\%) & 827 & \\
\hline Married & & 99.2 \\
\hline Education status (\%) & 829 & \\
\hline Primary or less & & 19.9 \\
\hline Intermediate & & 33.7 \\
\hline High school & & 23.4 \\
\hline University & & 20.9 \\
\hline Other & & 2.1 \\
\hline Employment status (\%) & 828 & \\
\hline Homemaker & & 77.3 \\
\hline Employed & & 2.2 \\
\hline Other & & 20.5 \\
\hline Place of birth (\%) & 704 & \\
\hline Urban & & 56.0 \\
\hline Rural & & 44.0 \\
\hline Place of residence (\%) & 704 & \\
\hline Urban & & 47.8 \\
\hline Rural & & 52.2 \\
\hline
\end{tabular}

$S D=$ standard deviation .

The mean birth weight of the index child was $3314 \mathrm{~g}$. Almost all mothers gave birth in a hospital (92.5\%). For $88.6 \%$ a physician was present to assist with the delivery. Delivery was by caesarean section in $22.9 \%$ of women, and $44.1 \%$ stated that they had been given analgesics during and/or immediately following the delivery.

\section{Breast feeding practices}

More than half (55.9\%) of the mothers reported that they initiated breastfeeding their babies within a few hours of birth, $18.3 \%$ within half an hour, and $21.2 \%$ a few days after birth; $4.6 \%$ of the sample did not breastfeed. A large number of mothers reported that physicians $(42.8 \%)$ or their own mothers (22.0\%) influenced their decision to breastfeed. Other sources of influence included: relatives (11.0\%), motherin-law (10.0\%), the media (7.0\%) and books (7.1\%).

More of the mothers who exclusively breastfed for the first 6 months of life were born in a rural than in an urban region $(57.1 \%$ versus $30.0 \%)\left(\chi^{2}=10.86\right.$, 
$P=0.012)$ and more were currently residents of rural areas (63.4\% versus $32.4 \%)\left(\chi^{2}=10.29, P=0.006\right)$. Overall, termination of breastfeeding was due to mother's beliefthat breast milk was insufficient for the infant (26.2\%) or belief that the child was old enough (21.0\%).

\section{Introduction of complementary foods: age and frequency}

The majority of infants in the study received solid foods at or beyond 4 months of age (Table 2). The proportion of infants introduced to solid foods below the recommended age was not large; the largest proportion were given cereals $(9.1 \%)$, followed by fruits $(7.8 \%)$ (Table 3). However, a large number had been given other fluids such as sweetened water and herbal teas (Table 4). Table 3 also shows that just over $5 \%$ of infants were given dairy and desserts below the recommended age.

Mothers who initiated breastfeeding early did not differ from those who initiated later with regard to age of weaning. However, those who breastfed longer, i.e. for more than 6 months, introduced cereals at a significantly later age [mean 6.7 (SD 5.5) months] than those who breastfed $\leq 5$ months $[$ mean 5.9 (SD 4.2) months] $(t=-2.05 ; P=0.041)$. Weaning onto other food groups was similar comparing the 2 breastfeeding groups.

Mean age of weaning was significantly different for all food groups when analysed by place of residence. Interestingly, for all food groups, mothers residing in urban areas initiated complementary foods earlier than those in rural areas (Table 5). Maternal place of birth, education level and employment status were other factors that significantly influenced the introduction of solid foods for some food groups (Tables 5 and 6). Mothers in employment outside the home introduced complementary foods at significantly younger ages than did homemakers. The mean age of weaning

\begin{tabular}{lcccc}
\hline \multicolumn{5}{l}{ Table 2 Age of infants at introduction of solid foods $(\boldsymbol{n}=\mathbf{8 2 7})$} \\
$\begin{array}{l}\text { Age at introduction of } \\
\text { solid foods }\end{array}$ & No. & $\%$ & $95 \% \mathrm{Cl}$ & Cumulative \% \\
$<3$ weeks & 4 & 0.5 & $0.01-1.0$ & 0.5 \\
$>3$ weeks and $<2$ months & 26 & 3.1 & $2.0-4.3$ & 3.6 \\
$>2$ and $<4$ months & 151 & 18.3 & $15.6-20.9$ & 21.9 \\
At 4 months & 344 & 41.6 & $38.2-45.0$ & 63.5 \\
At 5 months & 93 & 11.3 & $9.1-13.4$ & 74.7 \\
At 6 months & 111 & 13.4 & $11.1-15.8$ & 88.2 \\
$>6$ months & 98 & 11.9 & $9.6-14.1$ & 100.0 \\
\hline
\end{tabular}

$C l=$ confidence interval.

to solid food was also lower for mothers with higher levels of education.

Most of the mothers in the study (64.5\%) gave their children baby food every day; only $15.4 \%$ said that they never gave their children baby food. More than half the children were eating fruit (55.4\%), bread (57.1\%) and biscuits $(52.0 \%)$ every day. Other foods given every day were kaak (a kind of cracker-bread that is readily available in Lebanon) (28.5\%), desserts (17.8\%) and honey (13.3\%). The frequency of consumption of meats was relatively low, with $32.1 \%$ of the children never having beef, $21.8 \%$ never having chicken, $61.5 \%$ never having lamb, and $50.8 \%$ never having fish.

The food frequency data were subjected to 1-way analysis of rank scores to assess the distribution of foods consumed in the rural versus urban regions. Place of residence was chosen since for all food groups weaning age differed significantly between the 2 regions. The results revealed that children from urban areas consumed more of the following foods: fruit $(P=0.006)$, potatoes $(P$ $<0.001)$, carrots $(P<0.001)$, peas $(P$ $<0.001)$, spinach $(P<0.001)$, squash $(P<0.001)$, green beans $(P<0.001)$, rice $(P=0.048)$, baby food $(P=0.008)$, beef $(P=0.002)$, chicken $(P<0.001)$, muhalabiyeh (a Lebanese milk-based dessert $)(P<0.001)$ and mughli (a rice powder-based dessert $)(P=0.01)$. Children residing in rural areas consumed more bulgur (cracked wheat) $(P$ $<0.001)$, yogurt $(P=0.013)$ and other dairy products $(P=0.002)$.

Logistic regression was used to reveal some of the determinants of age at the introduction of solid foods (Table 7). Controlling for all the variables listed in the table, only maternal employment status was significantly associated with age at introduction of solid foods. Mothers who were employed were 1.78 times more likely to introduce solid foods at < age 4 months. Logistic regression also

\begin{tabular}{|c|c|c|c|c|c|}
\hline \multirow[t]{3}{*}{ Weaning food } & \multicolumn{4}{|c|}{ Age of weaning (months) } & \multirow{3}{*}{ Total } \\
\hline & \multicolumn{2}{|c|}{$1-3$} & \multicolumn{2}{|c|}{$\geq 4$} & \\
\hline & No. & $\%$ & No. & $\%$ & \\
\hline Cereals & 63 & 9.1 & 632 & 90.9 & 695 \\
\hline Fruit & 55 & 7.8 & 646 & 92.2 & 701 \\
\hline Dessert & 40 & 5.9 & 634 & 94.1 & 674 \\
\hline Dairy & 38 & 5.6 & 645 & 94.4 & 683 \\
\hline Vegetables & 32 & 4.6 & 661 & 95.4 & 693 \\
\hline Eggs & 16 & 2.4 & 646 & 97.6 & 662 \\
\hline Meat & 9 & 1.3 & 660 & 98.7 & 669 \\
\hline Legumes & 3 & 0.5 & 650 & 99.5 & 653 \\
\hline
\end{tabular}




\begin{tabular}{|c|c|c|c|}
\hline Fluid & No. & $\%$ & $95 \% \mathrm{Cl}$ \\
\hline Infant formula milk & 742 & 43.8 & $40.2-47.4$ \\
\hline Herbal tea & 739 & 41.8 & $38.2-45.4$ \\
\hline Sweetened water & 740 & 37.6 & $34.1-41.1$ \\
\hline Water & 742 & 36.3 & $32.8-39.7$ \\
\hline Orange blossom water & 741 & 27.7 & $24.4-30.9$ \\
\hline Juice & 743 & 10.4 & $8.2-12.6$ \\
\hline Powdered milk & 742 & 3.1 & $1.8-4.3$ \\
\hline Cow's milk & 740 & 1.1 & $0.3-1.8$ \\
\hline Other fluids & 614 & 1.5 & $0.5-2.4$ \\
\hline
\end{tabular}

$C l=$ confidence interval.

revealed that breastfeeding duration and place of residence were no longer significantly associated with age of introduction of solid foods.

\section{Discussion}

The importance of feeding patterns and practices during the first year of life cannot be overlooked; they lay the foundation for food consumption throughout life and influence subsequent growth, development and morbidity [9].

Our study examined foods used for complementary feeding in the low and middle socioeconomic groups in Lebanon, as well as demographic factors associated with the time of weaning. Over $70 \%$ of the mothers in this study initiated breastfeeding soon after birth. Although this figure is encouraging when evaluated against figures from another country in the region, Saudi Arabia [10], $41 \%$ of these mothers stopped breastfeeding within 6 months and the rest interrupted breastfeeding by 9 months. Over $13 \%$ of the mothers gave their infants other liquids such as water, sweetened water and herbal teas before the 4-month benchmark, which undermines the benefits received from breast milk or formula alone $[11,12]$. While the increased risk of diarrhoeal diseases associated with the early introduction of nonmilk liquids has been documented previously $[13,14]$, efforts to stop this practice have not been a priority for physicians or other health professionals. Almost $70 \%$ of infants in the sample were completely weaned before the recommended age of 1 year.

In this study, the majority of babies (41.6\%) were weaned shortly after 4 months of age. Although it is reassuring that most children were not introduced to solid foods too early, it also suggests that in many cases the infants' developmental cues may have been ignored and introduction of solid foods could have occurred abruptly. Physicians or health care workers in developing countries should encourage mothers to be aware of signs that the infant is ready for solid foods, rather than state that the child can (or must) start solid foods at the 3-month or 4-month wellchild visit, and reassure the mother that until 6 months of age the child can receive sufficient sustenance from breast/formula milk alone. The most common starting food was cereals, which was also seen more in formula-fed infants. But cereals were also used as a first food earlier than

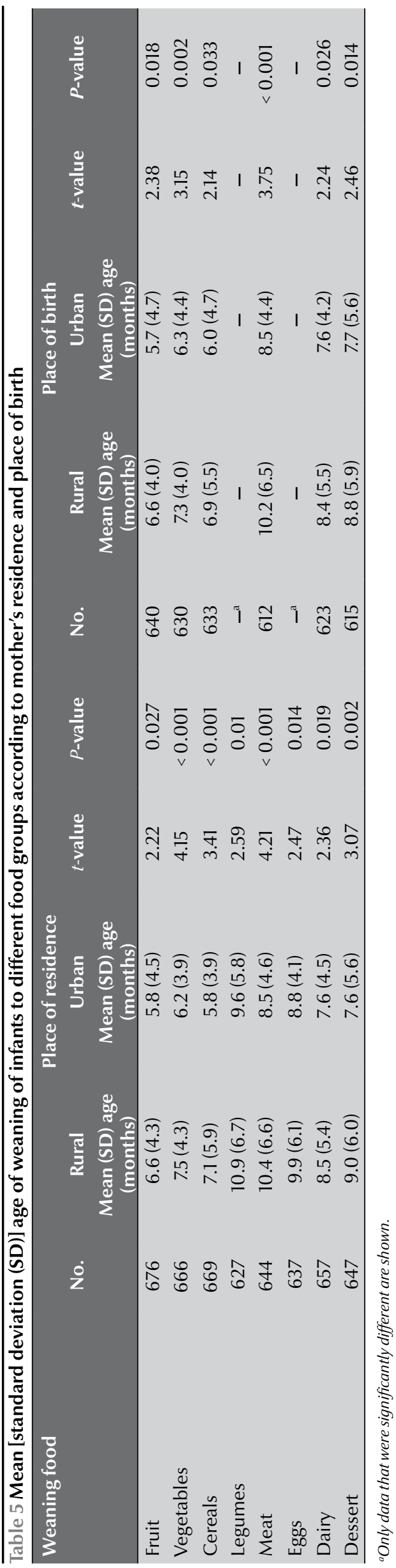




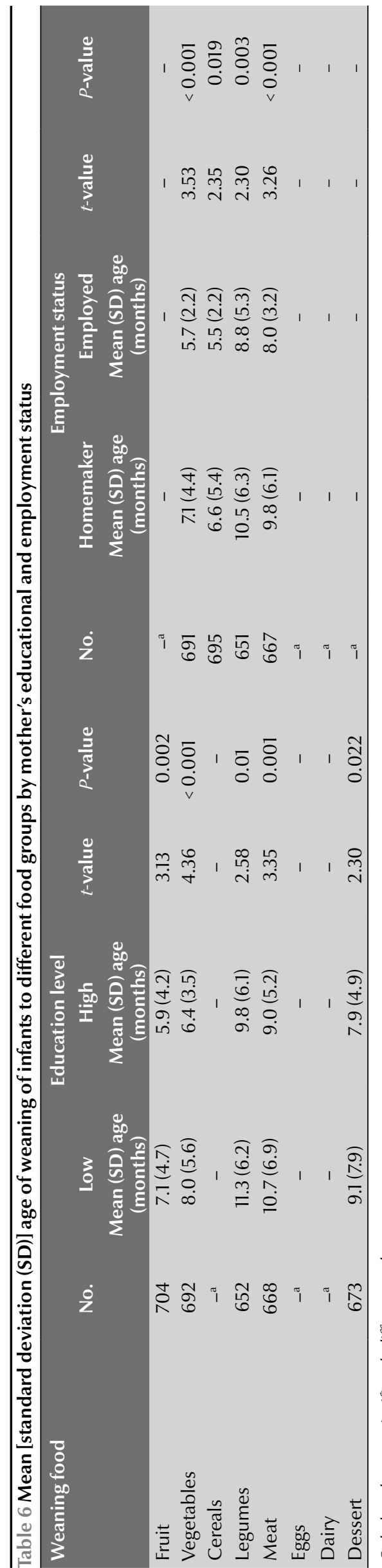

other food groups. Rice has been a principal supplementary food in several other Arab countries due to its availability and cost, as demonstrated by Abdulla in Iraq [15] and Wahiba et al. in Egypt [16]. Despite their level of education, mothers in these regions are typically concerned about the rate of growth of their babies. A study by Churchill and Kanawati reported that in Lebanon, a fat baby was regarded as healthy, hence cooked starches, especially rice with milk and sugar, were provided to young infants [17].

More disturbing, however, were the $21.9 \%$ of children who were introduced to solid foods and over $90 \%$ of children who were given other fluids before the recommended age of 4 months. These figures may be encouraging compared with data from other countries in the region-in Bahrain, about $62 \%$ of infants were introduced to solid foods at 3-6 months [18]. This is similar to data from developed regions, such as Norway, where $21 \%$ of the infant population were given solid foods before the age of 4 months [19], and similar findings in Germany [20] and the United States of America [21]. However, they do pose a predicament to a public health initiative to decrease, and preferably eliminate, food-related diseases such as diarrhoea, gastroenteritis and gastro-oesophageal reflux, among others.

Our data showed that place of residence affected the age of introduction of solid foods, with urban mothers introducing these at an earlier average age than mothers residing in rural regions. This was the case for all food groups. Although no explanations were found for this, it may be due to the fact that rural mothers breastfed for a longer duration and hence delayed the introduction of solid foods. There were certain foods that were actually consumed significantly more often in rural areas, such as yoghurt, other dairy products and bulgur, while foods consumed more often in urban areas were fruit, potato, carrots, peas, spinach, squash, green beans, rice, baby food, beef, chicken, muhalabiyeh and mughli. The avoidance of consumption of meats during infancy in rural areas could be due to traditional beliefs, such as those reported by Abdulrahman in Bahrain [18].

Table 7 Logistic regression analysis of the associations between infant's age at weaning and selected variables

\begin{tabular}{|c|c|c|}
\hline \multirow[t]{2}{*}{ Independent variable } & \multicolumn{2}{|c|}{$\begin{array}{l}\text { Age of weaning } \\
<4 \text { months } \\
\text { versus } \geq 4 \text { months } \\
\qquad(n=575)\end{array}$} \\
\hline & OR & $95 \% \mathrm{Cl}$ \\
\hline Mother's age $(1=\geq 30 ; 0=<30$ years $)$ & 1.29 & $0.85-1.98$ \\
\hline Mother's education level $(1=$ high; $0=$ low $)$ & 1.10 & $0.68-1.81$ \\
\hline Mother's place of birth $(1=$ urban; $0=$ rural $)$ & 0.96 & $0.59-1.56$ \\
\hline $\begin{array}{l}\text { Mother's current place of residence }(1=\text { rural; } \\
0=\text { urban })\end{array}$ & 1.53 & $0.94-2.50$ \\
\hline $\begin{array}{l}\text { Mother's employment status }(1=\text { employed; } \\
0=\text { homemaker })\end{array}$ & 1.78 & $1.01-3.13$ \\
\hline Type of delivery ( 1 = normal; 0 = caesarean section) & 0.78 & $0.44-1.37$ \\
\hline Breastfeeding duration $(1=\geq 6 ; 0=<6$ months $)$ & 0.00 & $0.00-1.95$ \\
\hline $\begin{array}{l}\text { Initiation of breastfeeding after birth }(1=\text { a few days; } \\
0=\text { a few hours }) \\
\text { Infant's sex }(1=\text { male; } 0=\text { female })\end{array}$ & $\begin{array}{l}1.42 \\
1.41\end{array}$ & $\begin{array}{l}0.80-2.52 \\
0.93-2.14\end{array}$ \\
\hline
\end{tabular}

Log likelihood $=548.49 ; \chi_{9}^{2}=47.99 ; \mathrm{P}<0.001$.

$O R=$ odds ratio, $C l=$ confidence interval. 
The large sample size enabled multivariate analysis that revealed maternal employment status as a highly significant determinant of early initiation of solid food in the low and middle socioeconomic groups in Lebanon. Mothers who were employed and those who were more educated initiated solid foods earlier than homemakers and those with less education. This phenomenon can be explained by the fact that the primary caregivers of these infants were most likely either the grandparents or day-care staff. More often, however, when the child is still very young (maternity leave is only 49 days in Lebanon) the grandparents are the first choice.
It should be noted that potential memory and recall errors may also have occurred as the mothers of younger children are more likely to be accurate in the information they provide compared with mothers of older children.

In conclusion, this study was successful in presenting a better understanding of the issues associated with the early introduction of solid foods to infants. Public health programmes and policies in Lebanon should address breastfeeding and issues concerning infant feeding processes for expectant and new mothers with short, clear and specific guidelines. A multidimen- sional approach that focuses on social, psychological, economic and personal concerns is an absolute prerequisite to ensure a supportive environment that will permit a mother to carry out the most favourable infant feeding methods.

\section{Acknowledgements}

This research was supported by grant DDF 112050-088223 from the University Research Board of the American University of Beirut. We are grateful to all the participants and interviewers who made this study possible.

\section{References}

1. Kramer MS, Kakuma R. The optimal duration of exclusive breastfeeding: a systematic review. Geneva, World Health Organization, 2002.

2. Gibson RS, Hotz C. The adequacy of micronutrients in complementary foods. Pediatrics, 2000, 106(Suppl.):1298-9.

3. Pelto $\mathrm{GH}$. Improving complementary feeding practices and responsive parenting as a primary component of interventions to prevent malnutrition in infancy and early childhood. Pediatrics, 2000, 106(5 Suppl.):1300.

4. Hop LT et al. Premature complementary feeding is associated with poorer growth of Vietnamese children. Journal of nutrition, 2000, 130(11):2683-90.

5. Yip R, Ramakrishnan U. Experiences and challenges in developing countries. Journal of nutrition, 2002, 132(4 Suppl.):827s-30s.

6. Implementation by FAO of some of the recommendations of the Plan of Action at the World Summit for Children. New York, United National Children's Fund, 2000 (http://www.unicef.org/ specialsession/documentation/documents/edr_fao_en.pdf, accessed 5 July 2009).

7. Yunis K, Khogali M, Tamim H. The first year of life (Aug. O1-Feb. 02 to Aug. 02-Feb.03). A study on morbidity and mortality among newborn babies, infants, and under five year old children in Greater Beirut, Lebanon. Beirut, Lebanon, Monographs of the National Collaborative Perinatal Neonatal Network, 2004.

8. World fact book. McLean, Virginia, Central Intelligence Agency, 2002.

9. Wright $\mathrm{AL}$ et al. Infant feeding practices among middle-class Anglos and Hispanics. Pediatrics, 1988, 88(3):776-80.

10. Fida NM, Al-Aama JY. Pattern of infant feeding at a university hospital in Western Saudi Arabia. Saudi medical journal, 2003, 24(7):725-9.

11. Batal $M$ et al. Breastfeeding and feeding practices of infants in a developing country: a national survey in Lebanon. Journal of public health nutrition, 2006, 9(3):313-9.
12. Batal M, Boulghourjian C. Breastfeeding initiation and duration in Lebanon: are the hospitals "mother friendly"? Journal of pediatric nursing, 2005, 20(1):53-9.

13. Jason J, Neiburg MP, Marks JS. Mortality and infectious disease associated with infant-feeding practices in developing countries. Pediatrics, 1984, 74(Suppl.):702-27.

14. Brown $\mathrm{KH}$ et al. Infant feeding practices and their relationship with diarrheal and other diseases in Huascar (Lima), Peru. Pediatrics, 1989, 83(1):31-40.

15. Abdulla SM. Food habits in Iraq [Master's thesis]. Alexandria, Egypt, High Institute of Public Health, University of Alexandria, 1979:100-7.

16. Wahiba SA et al. Improved feeding patterns in the prevention of childhood malnutrition. Gazette of the Egyptian Pediatric Association, 1975, 23(2):97-109.

17. Churchill CW, Kanawati A. Cultural factors in nutrition in Lebanon. Proceedings of the 6th symposium on nutrition and health in the Near East. Beirut, Lebanon, American University of Beirut, 1971:282-8.

18. Abdulrahman OM. Food habits in Bahrain: infants' feeding habits. Journal of tropical pediatrics, 1983, 29:248-51.

19. Lande B et al. Infant feeding practices and associated factors in the first six months of life: the Norwegian infant nutrition survey. Acta poediatrica, 2003, 92:152-61.

20. Kersting $M$ et al. Measured consumption of commercial infant food products in German infants: results from the DONALD Study. Journal of pediatric gastroenterology and nutrition, 1998, 27:547-52.

21. Hediger ML et al. Early infant feeding and growth status of USborn infants and children aged 4-71 mo: analyses from the third National Health and Nutrition Examination Survey, 1988-1994. American journal of clinical nutrition, 2000, 72:159-67. 